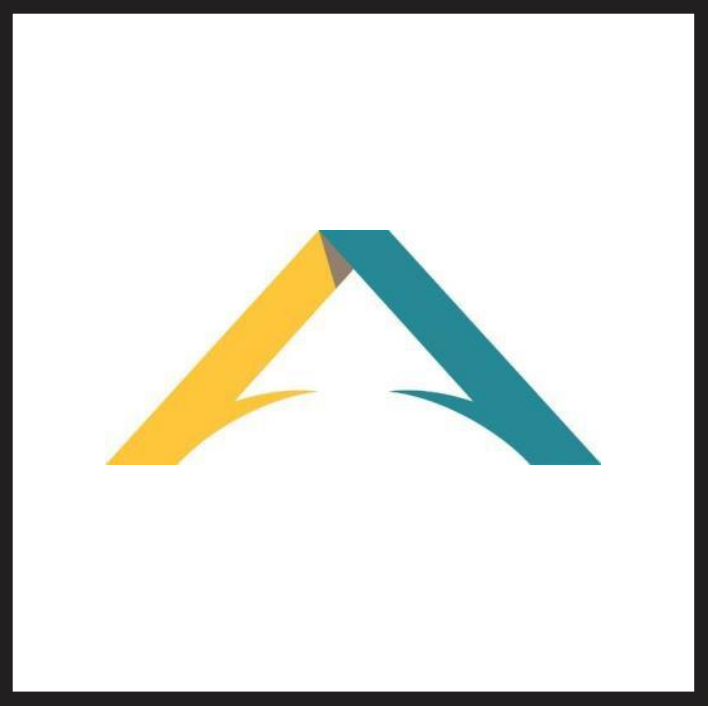

Revista

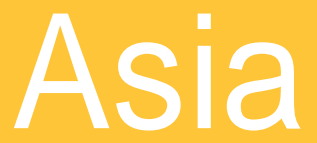

América

Latina

ISSN 2524-9347

Grupo de Estudios sobre Asia y América Latina Instituto de Estudios de América Latina y el Caribe Universidad de Buenos Aires

(c)

EU

DE BA 


\section{REFUGIADOS CAMBOYANOS EN LONGCHAMPS: TRAYECTORIAS DESDE INDOCHINA HASTA ARGENTINA}

\section{CAMBODIAN REFUGEES IN LONGCHAMPS: JOURNEYS FROM INDOCHINA TO ARGENTINA}

\section{Laura Puga \\ Universidad de Buenos Aires \\ lauramapuga@yahoo.com.ar}

Fecha de recepción: 30/04/2021

Fecha de aceptación: 06/07/2021

RESUMEN: Este analiza las trayectorias a un pequeño número de familias de origen camboyano, quienes formaron una comunidad tras asentarse en un barrio del Área Metropolitana de Buenos Aires, en la década de 1980. Procedentes de una zona de conflictos sucesivos y extremadamente violentos, en el norte de Camboya, se convirtieron en refugiados de Naciones Unidas, con acogida en Argentina. Se interpretan algunas violencias de aquel entorno y se pone en diálogo la bibliografía histórica, política y geográfica, con el trabajo de campo etnográfico. También se analiza el contexto particular de recepción, marcado por la última dictadura militar de Argentina.

PALABRAS CLAVE: refugiados camboyanos, trayectorias, comunalización, violencia, dictadura.

ABSTRACT: This paper analyses the journeys of a small number of Cambodian families that formed a community after settling in a neighbourhood of Buenos Aires Metropolitan Area (or AMBA) in the 1980s. Coming from a region of continuous and extremely violent conflicts in northern Cambodia, they became refugees under the United Nations with refuge in Argentina. Some of the violence from that context is interpreted and discussed with historical, political, and geographical literature as well as the ethnographic field research. The context of reception, marked by the last military dictatorship in Argentina, is also analysed.

KEY WORDS: Cambodian refugees, journeys, communalization, violence, dictatorship 
Refugiados camboyanos en Longchamps: trayectorias desde Indochina hasta Argentina LAURA PUGA

\section{Introducción}

Camboya es un país lejano en términos territoriales, pero también en sus aspectos culturales. Es sumamente infrecuente encontrar algún residente en Argentina que tenga ese origen, pero más aún lo es hallar un colectivo constituido por más de cien personas residentes en el barrio Rayo de Sol de Longchamps, en la localidad de Almirante Brown. Tal es el caso del colectivo al que se referirá este escrito.

Cuando inicié mi trabajo en la escuela de aquel barrio, en el año 2003, estaba vigente la Ley Federal de Educación 24.195 y existía un vínculo administrativo entre la escuela primaria y el Tercer Ciclo de la Enseñanza General Básica. Por este vínculo, los docentes de ambas instituciones compartíamos reuniones periódicas de personal. Fue en ese espacio que escuché por primera vez los relatos referidos a "los camboyanos", por parte de maestros primarios. Especialmente interesantes eran las narraciones del vicedirector de la escuela primaria, quien mantenía cotidiana comunicación con las madres de la comunidad educativa. Por entonces, aquellas "mamás camboyanas" apenas hablaban el idioma español.

Desde el lugar que ocupé como docente en el Secundario del barrio, se me facilitó la observación participante y el acceso a las entrevistas. Tuve estudiantes en la escuela, nietos de los refugiados llegados a Argentina desde Camboya y Laos. Llegaron al país matrimonios jóvenes con hijos muy pequeños, otros niños nacieron en Argentina y algunos de mis alumnos eran nietos de aquellos. Tres generaciones coexistentes desde la llegada; quienes se constituyeron como refugiados, con aproximadamente sesenta y cinco años, sus hijos de entre 35 y 45 años y los nietos. Durante la labor investigativa tomé contacto con las tres generaciones.

En la escuela aprendí a distinguirlos entre mis estudiantes de entonces, aún si no llevaban el apellido de origen camboyano, ni poseían un claro fenotipo indochino. ${ }^{1}$ Lo hacía observando su comportamiento social, lo que me llevó a pensar en ellos como comunidad. Haberlos reconocido entre su grupo de compañeros, puede estar vinculado a las modalidades en que los jóvenes transitan el proceso de comunalización y la manera en que lo actúan en la escuela; tal como interpreta Brow (1990) estos procesos. ${ }^{2}$

\footnotetext{
${ }^{1}$ El conjunto de caracteres visibles que los individuos de este grupo presentan, se identifica con facilidad entre los adultos de mayor edad, no así en individuos más jóvenes, aun cuando estos tengan el total de su genotipo (de padre y madre) camboyanos. La tercera generación, ya mestizada es de difícil reconocimiento. La característica más notoria que he notado es la baja altura.

2 A lo largo de la investigación se desarrolló el concepto de comunidad otorgado por distintos autores, tales como Brow, Anderson, Golluscio, Briones.
} 
A lo largo de la investigación se generaron fuertes vínculos de respeto y afecto entre los miembros de la comunidad y la investigadora. En algunas instancias de este escrito se puede leer el resultado del trabajo etnográfico en primera persona, producto del compromiso personal que se generó y del fuerte impacto que tuvieron y tienen los relatos de aquellos horrores. La investigación tuvo un enfoque histórico-etnográfico en el que se combinó el trabajo de campo con material estadístico, histórico y con otras fuentes. Ese enfoque permitió privilegiar el conocimiento que los involucrados tienen de los fenómenos sociales y reconstruir las lógicas que guían sus vidas cotidianas.

Este colectivo de personas a las que los vecinos del barrio y los docentes de la escuela reconocen como "camboyanos", está constituido por una mayoría de esa nacionalidad. Sin embargo, no todos lo son. Su estadía en un campo de refugiados de Tailandia duró por lo menos dos años. Durante ese tiempo se conformaron nuevas parejas, algunas de ellas con un integrante de otra nacionalidad, y nacieron niños en ese campo de refugiados, hechos que determinaron su posibilidad de acceder a la acogida en Argentina. ${ }^{3}$ Además de ello, a lo largo de los cuarenta años transcurridos desde su llegada, se integraron a las familias nuevos miembros de origen étnico diferente.

Las trayectorias de las familias "camboyanas" a las que se refiere este trabajo se iniciaron con la huida por tierra desde la provincia de Oddar Mean Chey, al norte de Camboya. Los integrantes de este grupo fueron, en su mayoría, de poblados muy cercanos al límite con Tailandia e iniciaron el escape entre 1977 y 1979. Lo hicieron en pequeños grupos o individualmente y de manera desesperada. Aquel contexto expulsor no solo determinó la huida, sino que impactó a lo largo de sus vidas, tanto en las representaciones que construyen sobre sí mismos como en las que construyen quienes los rodean y quien investiga (Debandi, 2013). Las vivencias por ellos narradas durante la investigación han sido resignificadas en un ejercicio de "recuerdos y olvidos singulares" (Jelin, 2002 , p. 3), que involucran una reconstrucción en la que se omite aquello que no encuentra lugar o sentido en el relato.

La investigación más amplia a la que se refiere este trabajo se centra en analizar las trayectorias de los refugiados camboyanos asentados en el Barrio Rayo de Sol de Longchamps, su devenir y constitución como comunidad articulada a partir de su llegada en 1980. En este artículo se espera describir el contexto histórico que motiva el éxodo y poner en diálogo el trabajo etnográfico realizado con la bibliografía académica acerca del tema, interpretando algunas maneras en que aquellos refugiados recién llegados a Longchamps han

\footnotetext{
${ }^{3}$ Para acceder a la condición de refugio y ser recibidos en Argentina, se requería que las parejas tuvieran por lo menos dos hijos, motivo por el cual varias de estas parejas tuvieron hijos allí o incluso adoptaron. Tal el caso de una de las entrevistadas quien adoptó un segundo hijo en Tailandia.
} 
Refugiados camboyanos en Longchamps: trayectorias desde Indochina hasta Argentina LAURA PUGA

rediseñado y extendido sus vínculos sociales, así como interpretar sus comportamientos y narrativas actuales en función de aquellos sucesos.

\section{El objeto de estudio: refugiados, comunalización e integración}

Los camboyanos llegados al país en 1980 lo hicieron en condición de refugiados. Este concepto tiene múltiples significados y está ampliamente desarrollado, aunque su descripción excede el propósito de este trabajo. Se han tomado ideas de Cicogna (2006), quien contribuye en ese desarrollo, ampliando la idea de que esta categoría de análisis está profundamente atravesada por la violencia. Para ella, el refugio puede estar originado también en "una violación de los derechos humanos de un colectivo de personas y [que esta situación] represente un temor fundado" (p. 104).

El pequeño grupo al que se aboca el estudio llegó al país durante el gobierno de la dictadura cívico-militar, en el año 1980. Este hecho es poco característico de tales gobiernos. Como dice Cicogna, “(...) el Estado argentino, en algunos momentos de su historia coincidentes con la asunción de gobiernos de facto o por fraude electoral, (...) cerró las puertas a los extranjeros". En el mismo párrafo agrega: "a partir de la reapertura democrática adoptó una posición favorable al ingreso de solicitantes de refugio y ha actuado para efectivizar su protección" (pp. 106). Esta interpretación ofrece un marco de cierta "rareza" en el análisis de la llegada de estas personas.

Una característica de la categoría "refugiados" especialmente tratada por Cicogna (2006) y que resulta de interés rescatar, es su vínculo con la violencia. La autora afirma que "Una persona refugiada puede ser violenta porque es producto de la violencia" (pp. 109). En este escrito se retomarán relatos de informantes que se ponen en diálogo con el contexto histórico, y otorgan sentido a la violencia transitada en el pasado.

En relación con el concepto de comunidad, se incorporan múltiples aportes. Entre ellos, los de Anderson (1993) fueron utilizados para recuperar los componentes imaginarios y simbólicos que se ejercen entre los miembros. En este trabajo se consideró integrantes del colectivo a quienes se reconocen como pertenecientes a la comunidad, aunque no necesariamente como "camboyanos". Las desigualdades existentes entre ellos no impiden que se formen lazos de profundo compañerismo y un sentido fraterno basado en la idea de horizontalidad y de profunda hermandad que caracterizó a las relaciones entre los refugiados camboyanos.

Por su parte, Golluscio y otros (1996) dicen que una comunidad se construye de modo procesual, en conflicto y diversificación de sus miembros. Brow (1990) desarrolla el concepto de comunalización a partir de los aportes que Weber (1994) formuló en torno a los tipos de relaciones que en ellas se 
producen. ${ }^{4}$ Para Brow, este proceso de comunalización se lleva adelante a partir de una manera de narrar el pasado que opera bajo condiciones económicas y políticas determinadas y modelan la conciencia de quienes integran una comunidad. En ambos trabajos, la comunidad se construye como un "sentido de pertenencia" que define algunos patrones de acción cultural históricamente determinada. Dicha idea de pertenencia involucra además versiones dominantes que circulan con relación a su propio pasado y que gozan de un mayor consenso al interior de las familias. Durante el trabajo de campo se observaron versiones y relatos del pasado que algunos entrevistados desarrollaron y todas ellas parecen ser compartidas o legitimadas por sus compañeros de grupo. Aquellos relatos que se nos ofrecían fueron emitidos por las voces genuinas, "con las que se debe hablar" denotando su legitimidad y traspasando las fronteras del recuerdo individual para convertirse en relatos colectivos.

Las conexiones existentes en este conjunto de personas tienen su expresión a través de la historia compartida. En el interior del grupo bajo estudio se conocen entre sí, se reúnen periódicamente, conocen los nombres de todos y/o el tipo de relación que los conecta. Se trata de una sociedad que alimenta sus relaciones en el "cara a cara" y aún constituidas en estos términos todas las comunidades tienen un componente imaginario (Brow, 1990) que en cierto modo traspasa la materialidad de los vínculos. Aun cuando la presencia de los integrantes de la comunidad haya variado a lo largo del tiempo y su convivencia no sea de contacto constante, cualquier miembro del grupo puede acceder a información disponible acerca de algún integrante, como un fondo común construido por "reputaciones". La reputación de algunos de los integrantes de este grupo usualmente se expresa en los relatos de los jóvenes que son nietos de los refugiados llegados en 1980 .

Brow (1990) advierte que el proceso de comunalización continuo puede tener lugar sobre diferentes bases. En esta pluralidad particular de personas, el pasado vivenciado en la nación camboyana, o lo sucedido posteriormente en Tailandia, así como el tránsito realizado por las diferentes familias hasta llegar al barrio Rayo de Sol, pudieron formar parte de un cúmulo complejo de experiencias a partir de las cuales se versionan recuerdos e identidades que varían según el período histórico, contexto o situación en el que son evocadas.

El pequeño grupo de refugiados asentado en Longchamps ha transitado muchas vivencias y nuevos miembros se han integrado a este colectivo; es por eso por lo que los lazos entre ellos se rediseñan constantemente. La vivencia de estos vínculos se ha podido advertir durante el trabajo de campo. En numerosas ocasiones fueron narrados y actuados en un lenguaje relativo al de las relaciones

\footnotetext{
${ }^{4}$ Weber realiza una distinción fundamental entre relaciones comunales, basadas en un sentido subjetivo de pertenencia y relaciones asociativas basadas en ajuste o acuerdos de intereses.
} 
familiares, poniendo en juego una definición parental que demuestra el grado de cercanía y afinidad entre las personas. Así lo evidencian los apodos con los que se tratan: "mi cuñada/mi cuñado", "primos" y demás, aunque no posean vínculo parental. Los jóvenes nietos de refugiados, todos ellos nacidos en la Argentina, se refieren a cualquier integrante de la primera generación como "abuelos", aun cuando sólo dos de ellos lo sean. En muchos casos los jóvenes desconocen el nombre de pila de los "abuelos" y se refieren a ellos por "abuelo-apellido". Naturalizan las relaciones a través del recurso a denominarlas en términos parentales y/o manifestaciones de cercanía afectiva.

Eduardo Page Poma (2015) estudia la manera en que se desarrolló un pequeño grupo de laosianos llegados a Argentina, procedentes de campos de refugio ubicados también en Tailandia. Estos laosianos fueron distribuidos por el territorio del país en base a las solicitudes de mano de obra recibidas desde las autoridades de distintas provincias. La intención que advierte Page Poma por parte de las autoridades estatales es generar un proceso de "integración" rápido, para luego ser enviados a explotaciones agrícolas al interior del país. En su trabajo se atiende especialmente a la "integración" de este grupo en el contexto de la última dictadura cívico militar.

\section{El contexto expulsor: guerra y violencia en Indochina}

Las condiciones históricas que dieron origen a la migración en cuestión deben interpretarse en el marco de la realidad regional del Asia comunista durante la posguerra, y esta situación obliga a realizar una lectura histórica que brinde sentido a los hechos. Se cuenta con escasa bibliografía disponible acerca del contexto de origen. Entre ellos se encuentra el texto de Ben Kiernan "El régimen de Pol Pot: raza, poder y genocidio en Camboya bajo el régimen de los Jémeres Rojos, 1975-1979”. Este texto específico del contexto de origen es citado por otros trabajos en casos similares de refugio de la ACNUR y también en relación con los laosianos asentados en la provincia de Misiones. Los aspectos históricos descriptos en ese texto caracterizan a la década del 60 y 70 en Indochina en torno al ascenso al poder del régimen de los Jemeres Rojos a través de la figura de Pol Pot. Este régimen tuvo dos naciones enemigas: Estados Unidos y Vietnam. Se mantuvo contrario a ambas a costa de la administración de una particular forma de terror que constituyó uno de los regímenes más opresivos y sanguinarios del siglo Xx, que resultó del desenlace de un golpe de Estado perpetrado en marzo de 1970 contra el gobierno monárquico de Sihanouk por parte del general Lon Nol.

\footnotetext{
5 Esta situación de estadía “de adaptación” que contempla Paga Poma (2015) fue mencionada por una entrevistada camboyana, se refirió a ella como de un mes de duración y localizada en Ezeiza.
} 
Kiernan (2010) afirma que en los años de guerra y dictadura en Camboya se rediseñan elementos de identidad nacional en oposición a la nacionalidad vietnamita. Todos esos episodios no pueden ser reducidos a la Guerra Fría debido a que, aunque esta incluye confrontación entre el mundo capitalista y el mundo comunista, aquellos exaltan la nacionalidad como elemento constitutivo en la Camboya comunista. Esto da origen a una "nacionalidad camboyana comunista" fundada sobre los principios de la Revolución Francesa y con la influencia ideológica del capitalismo central. Esta idea es compatible con las expresadas por Anderson cuando afirma que la invasión de Camboya realizada por los vietnamitas entre diciembre de 1978 y enero de 1979 era la primera guerra convencional en gran escala librada entre regímenes marxistas revolucionarios, "el ataque perpetrado por China contra Vietnam en febrero confirmó rápidamente el precedente" (1993, p. 17). Agrega: "Tales consideraciones ponen de relieve el hecho de que, desde la segunda Guerra Mundial, toda revolución triunfante se ha definido en términos nacionales: la República Popular de China, la República Socialista de Vietnam, etc.” (p. 18). Estas afirmaciones sustentan la necesidad de comprender los sucesos de Camboya en la década de 1970, no solo en el marco de la Guerra Fría, sino en el de enfrentamientos nacionales, entendidos como parte de la conformación de los Estados-nación en Indochina.

En relación con el golpe de Estado en Camboya llevado a cabo por los Jemeres Rojos, se debe mencionar la publicación de "Diario 90. Defendiendo la verdad desde La Habana. Cuba", con fecha 7 de marzo de 2012. Esta publicación de Jorge Wejebe Cobo ${ }^{6}$ realiza un análisis acerca de los sucesos de los años 70 con el título de "El año cero de Pol Pot". En este análisis se adjudica una gran relevancia al rol que Estados Unidos tuvo en las luchas de liberación de Vietnam y en la intervención de Camboya después, fundamentando el argumento en que hacia 1970 la neutralidad de Camboya era un estorbo para los Estados Unidos, pues pretendía evitar la circulación del ejército vietnamita comunista a través de tierras camboyanas. Por ello, la publicación arriba mencionada afirma que la Agencia Central de Inteligencia (CIA) organizó un golpe de estado contra el príncipe Norodom Sihanouk.

Las investigaciones o trabajos realizadas sobre los hechos políticos sucedidos en Indochina durante 1970 y 1980 no parecen contener grandes contradicciones entre sí, sino más bien centrar la atención del proceso en diferentes aspectos. Anderson centra el conflicto en la conformación de una nacionalidad moderna de acuerdo con las características regionales, que resultan tardías respecto a Latinoamérica y Europa. Además, sostiene que la cohesión se logra con herramientas diferentes a las utilizadas en otras regiones del mundo. Para Kiernan, el conflicto se centra en el carácter sanguinario y de extremo armamentismo, visto como un proceso particular y único, cuyos conflictos

${ }^{6}$ Disponible en versión digital en: https://eladversariocubano.net/ 
Refugiados camboyanos en Longchamps: trayectorias desde Indochina hasta Argentina LAURA PUGA

surgen del posicionamiento que Estados Unidos tuvo en el Sudeste Asiático y las características nativas de la resistencia.

En tanto, el periódico cubano arriba mencionado coloca el centro del conflicto en la intervención de Estados Unidos, su voluntad política de extender su dominio en el Sudeste Asiático y los "artilugios" que utilizó el ejército norteamericano para sortear las limitaciones que se sancionaron en su propio Congreso. Pone además el foco en los comportamientos autónomos de las fuerzas armadas imperialistas, cuyo principal interés fue/es el de fortalecer el negocio armamentista y consolidar su poder.

Se carece de análisis nativos del proceso. Esta carencia podría estar originada en la falta de traducciones a cualquier lengua occidental, en la tradición oral del Reino de Camboya y en la ausencia de un revisionismo acerca de este proceso por parte de las ciencias sociales en la sociedad camboyana. Es posible que todos los aspectos que enfatizan estos autores contribuyan a la complejidad del proceso histórico y político que afectó a los refugiados camboyanos en Argentina. Existen documentales y películas, a los que se alude en este escrito, pero ninguno de las cuales agrega nuevos análisis a los recién mencionados.

Para otorgar significado a la violencia de la que proceden los refugiados, es necesario conocer el trayecto de huida por tierra y las vivencias que los movilizaron a tal hazaña. A pesar de que los camboyanos refugiados en nuestro país fueron pocos, son numerosos los que huyeron de su tierra a través de Tailandia, especialmente durante la segunda mitad de la década de 1970. Según los datos publicados por ACNUR en La situación de los Refugiados en el mundo (2000), ingresaron por tierra desde Camboya hacia Tailandia 171.933 personas en condición de asilo. Son de especial interés las características históricas, territoriales y políticas llevadas a cabo en Camboya a partir de la década de 1960, cuyos orígenes son anteriores, como generadores de expulsión de personas. Pocos de ellos ingresaron a la Argentina en varios contingentes durante el año 1980. Aquel contexto expulsor impactó en las trayectorias de vida de los refugiados. Sus experiencias de procedencia fueron muy variadas, algunos de los entrevistados habitaban y trabajaban en sus pueblos de origen, en tanto otros yacían en campos de trabajo forzados.

La llegada de estos refugiados es poco común para los alrededores de la Ciudad de Buenos Aires, en términos de Pacecca (2013). Se la suele incluir entre la "inmigración reciente" procedente del Este Asiático. En Argentina, como en todos los países receptores de migración, la agenda política y periodística los tiene siempre presentes. Pacecca (2013) dice que esta y otras colectividades han sufrido el recrudecimiento de prejuicios étnicos y raciales, durante la década de 1990, especialmente por los duros embates periodísticos e institucionales. Estos prejuicios se reflejan, entre otras cosas, en la generación de noticias prejuiciosas, reduccionistas, estandarizadas y negativas acerca de estos inmigrantes. Esos prejuicios no salieron fácilmente a la luz en las entrevistas, en ningún caso se 
expresaron abiertamente con términos alusivos al fenotipo, que podrían considerarse prejuiciosos.

Durante la observación participante tuve múltiples charlas con vecinos del barrio. Especialmente AB fue muy cuidadoso en sus expresiones acerca del colectivo; buscaba las palabras adecuadas minuciosamente. Parecía esforzarse por no emitir ningún comentario que pudiera sonar como prejuicioso. Es posible que tal como Martino (2015) advierte para otra comunidad, existan mecanismos de invisibilización del racismo. Esto, según la misma Martino explica, puede estar originado en la idea de una Argentina de "brazos abiertos", un país de inmigrantes en el que el prejuicio racial está mal visto. Solo en algunos casos, las entrevistas dejaron ver argumentos prejuiciosos tales como la realizada a $\mathrm{DE}^{7}$, vecina del barrio, cuando dijo: "no eran capaces de afrontar con éxito la escolaridad" y también "cuando llegaron eran muy oscuros y con el tiempo se blanquearon". Otra vecina del barrio dijo: "No sé por qué ----- se casó con un camboyano, si es una linda chica, él es muy petiso, ella le lleva una cabeza de altura". Estas frases hacen referencia al color de piel y la baja estatura, características predominantes en este colectivo camboyano. Es posible que el racismo contra los camboyanos haya sido silenciado por ellos mismos también, por la vergüenza que les implica. Otro informante, SK, manifestó cierta incomodidad por expresarse en relación con sus vecinos. Ante la pregunta respecto a cómo fueron recibidos en el barrio, evadió la respuesta y siguió hablando de lo mal que fueron tratados en Camboya.

\section{El país de origen: el “año cero” de los Jemeres Rojos}

El Reino de Camboya es un pequeño Estado en la península de Indochina, que limita con Vietnam, Laos y Tailandia y posee costas sobre el golfo de Tailandia. Según Strahler (1982), su clima es tropical con estación seca en el invierno y tiene áreas de pluviselva, la estación seca es lo que diferencia este clima del ecuatorial y permite ciertas actividades de cultivo. Las costas de Indochina están bañadas por los vientos húmedos y tropicales que generan lluvias abundantes coincidentes con los momentos en que el sol está alto en el cielo, lo que otorga al ambiente temporadas de altas temperaturas y abundantes precipitaciones. Sus tierras están atravesadas de norte a sur por el río Mekong,

\footnotetext{
${ }^{7} \mathrm{DE}$ es la sigla con la que se refiere a una mujer que en el momento de la entrevista tenía aproximadamente 60 años y vivía en el mismo barrio. Ella había sido maestra en 4to grado durante la década del 1980 y recibió estudiantes camboyanos. Recordó muchas historias y nombres de quienes ahora tendrían 35 años aproximadamente. Fue llamativo el desconocimiento acerca de su condición de refugiados y los motivos que los llevaron a huir de su país. Esa escuela era y sigue siendo la más cerca al lugar en que originalmente se asentaron los refugiados, era inevitable que pasaran por allí.
} 
Refugiados camboyanos en Longchamps: trayectorias desde Indochina hasta Argentina LAURA PUGA

que nace en el Himalaya chino, recorre más de $4.200 \mathrm{~km}$ y desemboca en forma de delta en las aguas del Mar de China, en Vietnam.

Esta cuenca es fuente principal de recursos pesqueros. Se trata de un río navegable desde el mar por pequeñas embarcaciones hasta Phnom Penh, la capital de Camboya. Solo los barcos de poca profundidad pueden avanzar río arriba. El suelo fértil de la llanura deltaica y la abundancia de agua estacional son propicios para el cultivo de arroz. Recursos ambos (arroz y pescado) que determinaron la importancia que tuvo el país en el aprovisionamiento de comida para los soldados de uno y otro bando durante la guerra de Vietnam.

Hoy Camboya tiene algo más de quince millones de habitantes y transita por un recientemente iniciado proceso de democratización, en el que hubo pocos juicios contra los crímenes cometidos durante el régimen de los Jemeres Rojos. El 30 de enero de 2009, después de treinta años de la caída de aquel régimen, se inició el proceso judicial ${ }^{8}$, en un contexto de numerosas irregularidades políticas, crisis económica y el recrudecimiento de un conflicto fronterizo con Tailandia.

El régimen de los Jemeres Rojos tuvo dos naciones enemigas: Estados Unidos y Vietnam. Pol Pot se mantuvo contrario a ambas a costa de reprimir minorías étnicas, prohibir el islam, asesinar posibles aliados políticos y varios otros crímenes; todo en el marco de uno de los regímenes más opresivos y sanguinarios del siglo $\mathrm{Xx}$, y que resultó del desenlace de un golpe de Estado perpetrado en marzo de 1970 contra el gobierno de Sihanouk. Esto dio lugar al régimen de Pol Pot que, como dijo Anderson, contenía políticas de crueldad, paranoia, delirios de grandeza, despotismo y nacionalismo tendiente a conservar los intereses dinásticos imperiales?.

China y Vietnam competían por el liderazgo político en Indochina. En ese marco, la dictadura de los Jemeres Rojos que se inicia en Camboya a partir del golpe de Estado de abril de 1975 y perdura hasta 1979, se manifiesta antivietnamita. La rivalidad nacional con Vietnam parece pesar más que su similar tinte político, la procedencia étnica de la mayoría de su población o la

${ }^{8}$ En AAVV (s/f) bajo el título Primer proceso de una antigua autoridad jemer roja, se contextualiza el primer proceso judicial contra un autor de crímenes durante el régimen jemer rojo, se trató de "Duch", acusado por sus acciones como director del centro de detención S-21. Su nombre era Kiang Guek Eav. Durante el juicio que lo condenó tuvo la diabólica sinceridad de relatar sus torturas detalladamente. Fue condenado a cadena perpetua y murió en la cárcel el 2 de septiembre de 2020.

${ }^{9}$ Esta afirmación de Anderson, se replica también en otra bibliografía con relación a quienes estaban desconformes con el golpe de estado de Lon Nol, que derrocó al príncipe Sihanouk generando desconformidad por sectores monárquicos y tradicionales de la sociedad. Si bien la tendencia política de Pol Pot era comunista, prometió restituir en el gobierno al príncipe. Esta promesa y ciertos gestos propios de su formación lo ayudaron a obtener la connivencia de sectores conservadores de la sociedad. 
religión; pues la dictadura camboyana aceptó el patrocinio chino y se manifestó antivietnamita, al punto de fusilar aliados políticos de su misma etnia solo por tratarse de vietnamitas (Kiernan, 2010).

En el mismo texto se afirma que China de alguna forma patrocinó a la dictadura de Camboya de los Jemeres Rojos. Mao Tse-Tung contribuyó con armamento, alimentos y otros aportes al ejército de Pol Pot. Esto habla de un acercamiento entre el nacionalismo camboyano y el chino, alineados contra Vietnam. Por este motivo se considera que estos enfrentamientos no se explican exclusivamente por la Guerra Fría, entre los ejes comunista y capitalista, sino por rivalidades nacionales. Tal como afirma Anderson (1993), las revoluciones se definieron como "nacionales", la Revolución china y la vietnamita atan el proceso revolucionario a un pasado nacional heredado al que el autor define como "el valor más universalmente legítimo en la vida política de nuestro tiempo" (p. 19)

Los hechos violentos acontecidos en Indochina tienen una larga trayectoria. En 1867 el rey de Camboya solicita el ingreso al protectorado francés, con el objetivo de que sea Francia quien proteja al reino de otros posibles invasores. Entre los temidos invasores se encontraba el reino de Siam, actualmente Tailandia y Cochinchina. Ante la formación del protectorado francés y la inclusión de Camboya, Siam renunció a la soberanía sobre esas tierras y dio su reconocimiento oficial al nuevo protectorado. De esta manera lo relata el Diccionario Enciclopédico Hispanoamericano de Literatura, Ciencias y Artes:

No hay historia escrita de Camboya, pero la tradición asegura que hubo un tiempo en que este país fue el estado más rico y poderoso de Indochina oriental [...] Según los anales del Celeste Imperio, las primeras relaciones entre China y el Reino de Camboya datan del 616 d C. [...] entonces era un gran reino. Hacia 1670, comenzó a decaer. Combatido a su vez por Siam y Cochinchina que, poco a poco le fueron arrebatando territorios. [...] Cuando los franceses con la ayuda de los españoles lograron triunfar en Cochinchina y se establecieron en ella, el Rey de Camboya no vaciló en aceptar su protectorado que le había de poner al cubierto de los seculares enemigos de su

pueblo. (AA.VV., p. 326)

Durante la Segunda Guerra Mundial, Indochina fue ocupada por los japoneses, y es en ese contexto cuando Sihanouk es coronado rey en 1941. Tras la derrota de Japón, los franceses retoman el poder de su protectorado con gran debilidad política. En 1953 se firmó el Acuerdo de Ginebra, por el cual Francia reconocía como estados independientes a Camboya, Laos y los dos Vietnam. Esos largos años de influencia cultural francesa, especialmente entre las élites camboyanas, fueron y son aún muy importantes.

Para otorgar sentido a la dictadura ejercida por los Jemeres Rojos en Camboya es necesario mencionar algunas características y coyunturas. En primer 
lugar, su cercanía territorial al conflicto de Vietnam y el tránsito que los bandos del enfrentamiento tuvieron a través del territorio camboyano. Por otro lado, fue importante el desgaste político heredado de invasiones y ocupaciones anteriores, así como el ascenso al poder político de un sector social muy complejo, que fuera liderado por el conocido déspota Pol Pot o "Angkar", como él mismo se hizo llamar ${ }^{10}$.

Pol Pot nació el 19 de mayo de 1925, su nombre era Saloth Sar y sus padres eran propietarios de nueve hectáreas de arrozales, tres huertas y seis búfalos. Pertenecía a la etnia jemer, profesaba el budismo y mantenía contacto con la realeza. Tuvo una educación muy estricta y podríamos decir de privilegio entre sus coetáneos. Obtuvo una beca para estudiar en París en 1949, que perdió años más tarde. Sin embargo, durante su estadía en Francia conoció a quien después fue su esposa, se convirtió en miembro de la sección camboyana del Partido Comunista Francés y consolidó amistades. Ya de vuelta en Camboya, surge como líder político viable, cuando su fracción toma la conducción del Partido Comunista en 1963. Casi inmediatamente esta conducción pasa a una clandestinidad que le ofrece numerosas ventajas, tales como evitar cualquier debate político abierto, preparar la rebelión contra Sihanouk y formar alianzas con los enemigos de sus enemigos (Kiernan 2010). En 1967 ya estaba a la cabeza de la insurgencia comunista que generó un giro en la conducción del partido, conformando a partir de ese entonces una dirigencia de clase urbana, educada en Francia, radicalizada y antivietnamita.

El ascenso al poder de Pol Pot tuvo algunos antecedentes que debemos mencionar, dentro de los cuales es importante destacar la intervención del ejército norteamericano en la región. Su objetivo político era aislar a China, consolidando la hegemonía norteamericana en los países que la rodean, para limitar su poder, según lo expresa Kiernan (2010). A medida que el conflicto en Vietnam se intensificaba por la intromisión del ejército norteamericano, los soldados comunistas buscaban refugio en campos camboyanos, cuyo gobierno se mantenía neutral. Esperaban evitar los bombardeos del ejército estadounidense y obtener comida, especialmente arroz procedente de los campos del noroeste. Un poco más tarde, en 1966 se iniciaron incursiones norteamericanas de aviones bombarderos B-52 en el campo camboyano cercano al límite con Vietnam. Y aunque Kiernan dice que el objetivo era llevar a los soldados comunistas nuevamente al campo de batalla, otras versiones hablan de bombardeos anteriores y con intenciones confusas. Estas incursiones del ejército norteamericano, cada vez más frecuentes, y la crisis económica que generó el aumento del contrabando de arroz, desgastaron fuertemente al gobierno de Sihanouk y disminuyeron los recursos económicos disponibles de la nación.

\footnotetext{
${ }^{10}$ Angkar podría ser traducido como "la organización".
} 
Con el apoyo de Estados Unidos (y el silencio complaciente de la oposición política de Pol Pot), el 18 de marzo de 1970 el general Lon Nol derrocó al príncipe Sihanouk y se instaló en el poder, usurpando el gobierno camboyano. A pesar de la manifiesta colaboración de Estados Unidos con el nuevo gobierno de Lon Nol, el ejército estadounidense intensificó los ataques de B-52, sembró minas personales en campos camboyanos, en el marco de las misiones "Salem House" primero y "Daniel Boom" después. Las operaciones militares realizadas fueron ochocientas solo en el año 1967 (Kiernan, 2010); causaron terror y confusión en la población.

En la entrevista realizada por Miguel Riera el 3 de noviembre de 2009 a Mark Aguirre, autor del libro Camboya. El legado de los Jemeres Rojos, este último dijo:

El caso camboyano es una vergüenza más de tantas para nosotros los occidentales, los supuestos civilizadores que rompemos las leyes cuando queremos y exigimos cumplirlas a nuestros supuestos enemigos. Por los últimos documentos desclasificados por el Pentágono se sabe que Camboya tiene la desgracia de ser el país más bombardeado de la historia. Más que Japón, incluyendo las bombas atómicas, y más que Alemania, durante la segunda guerra mundial. No olvides que Camboya es un pequeño país, un poco más grande que las dos Castillas juntas. Es difícil saber los muertos que hubo, pero la cifra generalmente aceptada por los historiadores alcanza el medio millón. Tanta destrucción arrasó la sociedad rural. La ciudad, que apoyaba a los norteamericanos, se libró de las bombas, facilitando el camino a los jemeres rojos. Pero lo patético es que Johnson primero y después Nixon nunca lo hicieron público para no alimentar al movimiento contra la guerra de Vietnam, que veían como una amenaza interna. Cuando Martin Luther King fue asesinado en 1968 estaba en el proceso de unir el movimiento por los derechos civiles al movimiento contra la guerra de Vietnam, una alianza explosiva. El mismo Congreso estaba contra la expansión de la guerra. Es en este contexto que decidieron actuar contra la legalidad; según la Constitución los Estados Unidos de América no pueden atacar a un país sin declararle la guerra, actuando como rufianes protegidos por la oscuridad. Al final la guerra ilegal de Camboya fue un elemento más de los que afortunadamente hicieron caer al presidente Nixon. ${ }^{11}$

La descripción anterior es una de las tantas referidas a la violencia padecida en Camboya. El letrado español Miguel Ángel Rodríguez Arias, impulsor de la causa judicial que espera recuperar cuerpos de asesinados por el franquismo español entre 1936 y 1974, afirma que "España es el segundo país del mundo en fosas comunes tras la Camboya de Pol Pot". Esta afirmación fue

\footnotetext{
${ }^{11}$ Nota disponible en: http://www.rebelion.org/noticia.php?id=94488
} 
Refugiados camboyanos en Longchamps: trayectorias desde Indochina hasta Argentina LAURA PUGA

tomada como propia por el movimiento memorista español, sintetizando con ella a dos grandes genocidios y sus secuelas enterradas en fosas comunes y aún impunes.

Respecto a la confusión generada por las operaciones norteamericanas acerca de quien o quienes eran responsables de los ataques a poblados en Camboya, se han encontrado en esta investigación múltiples fuentes. $\mathrm{SK}^{12} \mathrm{y}$ $\mathrm{ChS}^{13}$, informantes de la comunidad de Longchamps, se manifestaron en este mismo sentido. Ambas afirmaron no entender del todo la situación política que las obligó a huir, tampoco conocer la identidad de los batallones que ingresaban a los pueblos vecinos, y que cuando llegaban mataban a todos los que encontraban. Es posible que esta confusión esté basada en que algunas veces los soldados americanos o sus aliados vietnamitas que intervenían en estos operativos "vestían uniformes de Viet Chong", es decir, del ejército contrario (Kiernan, 2010, p. 65). Con Lon Nol en el poder, y sin indicadores previos que pudieran anticiparlo, el ejército de Estados Unidos invadió Camboya generando "en 1971, 130.000 refugiados jemeres", ante las Naciones Unidas.

Según Kiernan, los ataques cada vez más frecuentes originaban tal malestar que los sobrevivientes eran fácilmente captados por el Partido Comunista de Kampuchea, liderado por Pol Pot. Las operaciones de inteligencia norteamericanas, las plantaciones de minas y los bombardeos facilitaban el reclutamiento. A este respecto, múltiples artículos de The New York. Times hacen referencia a esta situación y los entiende como factores de presión para la elaboración de la ley del Congreso de Estados Unidos, del 15 de agosto de 1973, en la que se ordena el cese del fuego y el retiro de las tropas norteamericanas de Camboya.

Acerca del rol que Estados Unidos tuvo en Camboya, hay dos películas de ficción que evocan la situación de violencia vivida en Camboya y son de interés para el tema, la más antigua titulada Los gritos del silencio (1984), enfocado en la repercusión mediática que generó el golpe de estado de Pol Pot. La segunda y más reciente es First they killed my father (2017), muy bien documentada y con

\footnotetext{
${ }^{12} \mathrm{Sk}$ es la sigla con la que se designa a una mujer refugiada de entre 62 y 65 años. Es abuela de varios de mis alumnos, se anunció en la escuela cuando se enteró por la directora que yo estaba haciendo trabajo etnográfico con miembros de la comunidad camboyana. Fue mi primera entrevista a un miembro de la primera generación de esta comunidad, sus dificultades para expresarse en español son moderadas, en relación con otras mujeres de la primera generación de esta comunidad que entrevisté más tarde.

${ }^{13} \mathrm{ChS}$ es la sigla con la que se refiere a una mujer de la primera generación de la comunidad, también tiene entre 62 y 65 años, ella asistió a la escuela a mi pedido, realizado a través de su nieta. Vino acompañada de otra mujer de la misma edad, a quien se refiere en este trabajo como Lam. Ambas fueron acompañadas por la hija de ChS, presentada como S, madre de una de mis alumnas.
} 
una tibia mirada crítica respecto de la intromisión de Estados Unidos en la región. Son pocas las manifestaciones artísticas que llegaron al mundo occidental de aquel genocidio. Es pertinente recordar que las intervenciones americanas en Camboya durante las décadas de 1960 y 1970 son aún causales de acusaciones judiciales dirigidas al entonces embajador ${ }^{14}$ de Estados Unidos, según se puede leer en The New York Times ${ }^{15}$.

Durante 1966 se había producido un bloqueo marino de los Estados Unidos sobre la costa de Vietnam, que impedía la conexión por barco entre los vietnamitas comunistas del norte y del sur. Es entonces cuando construye la ruta terrestre de Ho Chi Minh, también llamada por los norvietnamitas la "599". Se trata de una red de caminos trenzados de aproximadamente 20.000 kilómetros de extensión total, que unen la ciudad de Hanoi con Saigón. La circulación de tropas comunistas por esta red de caminos sobre territorio laosiano y camboyano fue extremadamente difícil de atacar por parte de norteamericanos que bombardeaban de forma constante. Este bombardeo creciente que los aviones americanos realizaban vulneraba el acuerdo de neutralidad de Laos y Camboya. La intromisión americana por este camino causó tal descontento entre los camboyanos y laosianos, que favoreció el reclutamiento de comunistas en ambos países y la creciente fuerza política comunista que sería fundamental más adelante $^{16}$.

La zona norte del país fue reiteradamente bombardeada. Una mañana de febrero de 1973 los B-52 atacaron la aldea de Stung Kambot (también denominada Pnum Kambot) al sur de la región de Oddar Men Chey. Allí asesinaron a cincuenta aldeanos e hirieron de gravedad a treinta. Más tarde, en marzo, los B-52 y los F 111 bombardearon una caravana de carros de bueyes en el mismo distrito, momento en el que mataron a diez aldeanos más: "un joven campesino recordaba como los B-52 bombardeaban su aldea entre tres y seis veces por día durante tres meses" (Kiernan, 2010, p. 72). El norte del país fue una región especialmente perjudicada por los ataques aéreos, la confusión y el terror. La provincia de Oddar Mean Chey es el lugar de residencia de origen de algunos refugiados, hoy residentes en Longchamps, según los registros de campo realizados. Aquellos sobrevivientes que no se convirtieron en partidarios del

\footnotetext{
${ }^{14}$ Bajo las órdenes del entonces secretario de Estado Henry Kissinger, Thomas Enders fue jefe de la misión norteamericana en Camboya entre 1971 y 1973, años en que Estados Unidos bombardeó en secreto zonas ocupadas por fuerzas de Vietnam del Norte. Después fue acusado en el Congreso de haber hecho todo lo posible por obstaculizar las investigaciones sobre tales bombardeos. El País, 19/3/1996.

15 The New York Times (1 de marzo de 1982) Columna de opinión editorial, "American Embassy's Role in the 1973. Bombing in Cambodia”.

${ }^{16}$ Kiernan dice: "el 60\% de los encuestados en Ciudades de Camboya daba como causa principal de su desplazamiento el bombardeo de los Estados Unidos” (2010, p. 67).
} 
Partido Comunista de Kampuchea de Pol Pot, fueron captados como mano de obra en los campos de trabajo, exiliados o asesinados. Durante los años de su gobierno ejecutaron a camboyanos no jemeres, incluso a quienes tenían alguna experiencia revolucionaria, como una "limpieza étnica".

Durante una entrevista le pregunté a SK acerca de su adscripción étnica. Respondió inmediatamente con actitud defensiva: "¡Yo no soy jemer!". Al responder cambió el tono de voz y me hizo notar su disgusto por la pregunta. También dejó claro que serlo constituye algún tipo de deshonra entre el grupo. Esta comunidad es un heterogéneo étnico, social y económico, que se define hacia el barrio por su nacionalidad y no por su origen étnico o religioso, ni por su condición de "refugiados". Posiblemente su rápido distanciamiento de la adscripción a la etnia jemer tenga lugar en la asociación generalizada que existe entre la dictadura de los jemeres rojos y la extrema violencia de la que la comunidad fue producto.

En Camboya, los jemeres mantenían los privilegios y quienes no lo eran fueron perseguidos. "No se trataba ni de una revolución proletaria comunista que privilegiaba a la clase trabajadora, ni de una revolución campesina que favorecía a todos los granjeros. Los favores en Kampuchea Democrática, tal como se daban, estaban reservados para los jemeres aprobados" (Kiernan, 2010, p. 77). Nunca se explicitó el significado de "aprobados", pero con seguridad los refugiados de este estudio no lo eran.

Con la toma del gobierno por parte de Pol Pot y el ingreso de los soldados a las ciudades, obligaron a la población urbana a abandonar sus casas a la fuerza, sin un destino claro, solo debían alejarse tres $\mathrm{km}$ de la ciudad. Los extranjeros que residían en Phnom Penh fueron reunidos en la embajada francesa y expulsados días más tarde. Para realizar estas difíciles maniobras utilizaron el pretexto de posibles bombardeos norteamericanos, y así evacuar en pocos días a la población de dos millones de habitantes que poseía la ciudad capital Phnom Penh en ese momento. La evacuación fue caótica y, de acuerdo con el cálculo realizado por Kiernan la tasa de mortalidad del viaje fue muy alta, equivalente en números absolutos a 10.600 personas muertas o ejecutadas durante el éxodo. Algunos de los habitantes expulsados de las ciudades fueron enviados a zonas menos pobladas del norte, con cuyo trabajo esperaban producir y exportar dos millones de toneladas de arroz en 1977.

Para Aníbal Quijano (2000), la colonialidad es un elemento constitutivo del patrón mundial de poder capitalista y Camboya durante el gobierno de Pol Pot fue comunista. Sin embargo, para este autor, la colonialidad se funda en la imposición de una clasificación racial o étnica de la población que se mundializa a partir de la conquista de América. A pesar de la aparente imposibilidad de aplicar la idea a este caso, se intentará dar sentido a las narraciones de los refugiados a la luz del concepto de colonialidad. En primer lugar, porque la supremacía de los jemeres rojos educados en Francia fue parte fundamental en 
la estructura de dominación durante los años de dictadura de Pol Pot (por lo menos). La expulsión de extranjeros, los discursos acerca de la nueva Camboya que la situaban distanciada del mundo occidental, pero también del mundo comunista podría interpretarse como una imposición de superioridad étnica. Los camboyanos no jemeres y campesinos fueron relegados, fusilados, expulsados u obligados a trabajar en situaciones de subordinación extrema. Recordemos que todas las escuelas del país fueron cerradas, las expresiones de arte prohibidas, los disidentes asesinados, los extranjeros expulsados. Las pertenencias privadas con algún valor económico o artístico fueron inmediatamente apropiadas por el régimen de los jemeres rojos.

Es posible interpretar que la racionalidad eurocéntrica reinante en el poder de Camboya ${ }^{17}$ durante fines de la década de 1970, fue un elemento de dominación utilizado por Pol Pot y su círculo de poder. En tanto la población del país se vio privada de finalizar su escolaridad, dando así legitimidad a la "superioridad intelectual" de la clase dirigente, los campesinos no disponían de escuelas para sus hijos y la dirigencia política educada en Francia marcaba el rumbo a seguir.

El eurocentrismo en la dirigencia camboyana se manifiesta, además, en el fortalecimiento de la identidad nacional, que se rediseña en contraposición a la vietnamita. Esta idea, que se convierte en emblema del gobierno de los jemeres rojos, se sustenta en una rivalidad con Vietnam que con algunos antecedentes históricos se fortaleció como producto del alineamiento con China a partir del golpe de Estado de Pol Pot.

Durante mis observaciones de campo tuve la oportunidad de escuchar relatos de la huida. SK me transmitió con el suyo angustia, hambre y desorientación. Ella estaba abandonando a sus dos hijos pequeños en el pueblo que dejaba, aunque más tarde logró recuperarlos y su recuerdo está cargado de aquella sensación. El relato de ChS ponía énfasis en el miedo, el hambre y el dolor físico. En todos los casos, el tiempo transcurrido durante el relato de la huida me transportó al lugar y al momento en presente. Estos relatos estaban marcados por la desposesión, la subordinación y el terror creciente, todo ello cobra sentido ante la decisión de cruzar a Tailandia.

Cuando inicié el trabajo de campo me preguntaba: ¿por qué esta minoría sigue definiéndose "no jemer" en un contexto que desconoce todo significado de esa identidad? El primer sentido que le di fue que, en el barrio nadie lo preguntó. También pensé que su adscripción era una muestra política que los excluye de cualquier asociación con los jemeres rojos. Así, encontré sentido a su expulsión, en la desposesión de bienes, propiedades, bienestar, paz, y hasta

17 Según Kiernan (2010), la admiración de Pol Pot por la Revolución Francesa lo llevó a elegir el día de la Toma de la Bastilla para su boda con una camboyana que conoció en Francia. 
incluso de la pertenencia a la etnia jemer. Por otro lado, su adscripción a la nacionalidad camboyana en Argentina al igual que en cualquier lugar del mundo es indiscutible y universalmente admitida. Puede ser que todo lo dicho sea motivo de cierta aceptación de la comunidad a ser denominados "camboyanos", en vez de refugiados, indochinos, jemeres u otra denominación.

Posiblemente la entidad histórica de esta etnia los haya vinculado, tanto allá como acá, con la clase oprimida. Definirse no jemer puede ser una forma más de evidenciar la desposesión padecida, aun cuando entre sus vecinos del barrio no se le diera tal significado. Durante el trascurso de las observaciones participantes escuché comentarios acerca de los miembros de la comunidad y nunca se refirieron a ellos por su etnia, siempre lo hicieron por su nacionalidad.

Así, su identidad étnica continúa refiriéndose a su situación allá, reafirmando la nacionalidad camboyana "no jemer"; reafirman que son sobrevivientes de crímenes perpetrados contra "su" gente y que no participaron de ninguna ventaja durante los años de Pol Pot. Esta identidad tan marcada entre la generación de los refugiados ${ }^{18}$, parece estar ausente entre las siguientes generaciones. No se trata de una "mezcla" étnica que los hizo desaparecer, sino de una identificación propia de la generación que padeció la condición persecutoria y que compone la otredad, en notable diferencia con sus hijos y nietos. Díaz Polanco hace referencia a esto y dice: "puede observarse que ciertos grupos mantienen constante una identidad contrastable con respecto a otros conjuntos sociales, pero eso no significa necesariamente que la identidad que establece el contraste es siempre la misma" (1988, p. 66). Lo que puede ser constante es la existencia de una identidad que funda la diferencia, pero la naturaleza de esa identidad en cada momento histórico es impactada por las transformaciones que sufre la estructura social.

\section{La llegada: un nuevo "año cero"}

Cuando SK aceptó darme una entrevista desconocía su experiencia en Camboya en la década de 1970. Ese fue mi primer contacto con una persona que transitó la huida. Me ocupé de dejarle claro que sus nietas, que eran entonces alumnas mías, no tenían nada que ver con mi voluntad de hablar con ella. Eso que yo sentí una obligación decirle, resultó en un lazo afectivo que facilitó el diálogo y generó de allí en adelante un vínculo de confianza. Una de las primeras advertencias que hizo SK me pareció exagerada: no quería hablar de lo sucedido en Camboya. Para ella la vida empezó el 13 de enero de 1980, el día que llegaron

${ }^{18}$ Me refiero a la generación de quienes hoy tienen entre 60 y 65 años y eran adultos jóvenes al momento de la huida, por tanto, conscientes de lo que sucedía, tomaron su propia decisión. Respecto a esto parece ser distinta la mirada de quienes huyeron con muy corta edad o nacieron en Argentina. 
al aeropuerto de Ezeiza (Buenos Aires) y no quería hablar de lo sucedido antes de ese día.

Hablamos más de una hora. Fue agotador, porque la barrera del idioma fue grande: a veces ella no encontraba las palabras y utilizaba miradas y gestos para enfatizar aquello que no podía verbalizar. Yo me anticipaba con intención de facilitar las palabras, sintiéndome muy torpe e incómoda ya que pocas de mis propuestas resultaron útiles. Todas esas herramientas fueron utilizadas por SK, para dar fuerza a aquella frase: tres o cuatro veces a lo largo de la entrevista repitió que su vida se inició el 13 de enero de 1980. Su insistencia, el énfasis en el tono de voz y la mirada, me dio indicios de que no se trataba de una afirmación como las otras y traté de buscarle sentido.

Pensé que podía tratarse de un agradecimiento a la Argentina por darle paz a su vida, que los sucesos vividos por ella en Camboya habían sido extremadamente dolorosos o vergonzosos y/o humillantes y no hablaría de ellos conmigo. También pensé que ese 13 de enero había sido crucial para su familia, pues había reunido a sus hijos y a partir de ese momento podría pensar en un futuro para ellos. Muchas cosas pasaron por mi mente cuando trataba de dar sentido a aquella insistente frase de SK. Lo llamativo fue que sí hablo de lo sucedido en su pueblo, de lo mucho que lamenta no haber vuelto a ver a su padre. Respecto a eso dijo: "Hablo por teléfono todos los meses con mi hermano, mi padre murió, pero mi hermano sigue viviendo en Kumon”. Relató algunos detalles de los familiares que se quedaron, de su madre que murió cuando ella era niña. Además, describió minuciosamente la huida. También habló sobre su vida de niña, sus juegos y su relación con el hermano: "Era una vida sencilla, pero éramos felices".

Meses más tarde, volví a pensar en sus palabras y encontré un nuevo sentido. Con la llegada de Pol Pot al poder, se exterminaron aldeas completas, asesinaron simpatizantes de Vietnam, Estados Unidos, la URSS o de casi todos los países del mundo. Las ciudades fueron evacuadas y los habitantes fueron enviados a campos de concentración donde eran obligados a trabajar. Se prohibió la moneda, el comercio, el mercado, las escuelas, la literatura, toda forma de arte, cultura y religión. El país se llenó de centros de torturas y ejecuciones, instalados en escuelas. La política oficial decía que solo la vida en el campo, lejos de la comodidad de la vida moderna occidental, era posible en la nueva Camboya, enfatizando sus aspiraciones fundacionales. Incluso cambió el nombre de la nación por el de Kampuchea Democrática y designó el inicio de su gobierno como el año cero.

Todo lo sucedido antes de la llegada del régimen de los jemeres rojos, quedaba anulado. Esta categoría instalada como estrategia de poder, atravesó a los sobrevivientes de tal manera que SK adoptó su propio año cero. "Le otorgo un nuevo sentido al 13 de enero de 1980”. Ella reemplazó el año cero de Pol Pot por un nuevo año cero en el que ella y su familia comenzaron una nueva 
trayectoria de vida. Este descubrimiento me enojó conmigo por no haber advertido algo tan obvio desde el mismo momento en que lo dijo, más tarde me alegré porque pude advertirlo y finalmente me emocionó la posibilidad de cambio que SK estaba realizando en su vida, pues el concepto de año cero que la acompañó en su trayectoria de vida en Camboya había sido resignificado perdiendo la carga de terror y amenaza que contenía en la política de Pol Pot para adoptar una apuesta por la vida.

\section{Dictaduras: expulsión y recepción}

El 9 de octubre de 1975 la Comisión Permanente de Camboya le otorga poder absoluto a Pol Pot sobre el ejército y la economía. Comienza un período de crímenes conocido como el genocidio camboyano, durante el cual se produce la muerte de aproximadamente una cuarta parte de la población total del país y el éxodo de miles de personas entre quienes se encuentran las familias residentes en Longchamps. Según Capote, en el Diario 90, de La Habana, del 7 de marzo de 2012: "La mayoría de la comunidad internacional guardó silencio alrededor del holocausto en Kampuchea, mientras que en el contexto de la Guerra Fría se jugaba un complejo ajedrez, sobre un tablero ensangrentado por millones de víctimas en el país".

El 24 de marzo de 1976, a partir del golpe de Estado que quiebra el orden institucional argentino, se instala en este país una dictadura cívico militar. Durante ese período, el país se caracterizaba por constituirse en emigrante (Pacecca y Courtis, 2008), lo que contrastó con la llegada de esta comunidad. Además, a partir de la década de 1960, el Área Metropolitana de Buenos Aires (AMBA) recibió principalmente migrantes de países limítrofes de varias provincias del país, junto a algunas minorías de otras nacionalidades. Entre ellos, refugiados procedentes de Laos y Camboya, pequeñas y aisladas comunidades con suertes diferenciadas de acuerdo con la zona y el carácter de sus trayectorias laborales. La Dirección Nacional de Población (2012), contextúa la llegada de estos refugiados en el marco del arribo de la Comisión Interamericana de Derechos Humanos.

El contexto de llegada de la comunidad constituye una particular contradicción: mientras Argentina se convertía en un país expulsor de población por causas políticas y económicas bajo una dictadura, recibía refugiados políticos de Indochina. Comprendiendo o no la situación política local, los refugiados debieron desenvolverse (los primeros tiempos por lo menos) con la exclusiva ayuda de la ONU y del Estado argentino, pues carecían de recursos propios y/o de la capacidad de generarlos (según lo que algunos informantes narraron, la barrera del idioma les parecía en aquel momento, infranqueable). Esta contradicción su suma a un doble gesto del Estado, quien se muestra solidario 
ante la ONU, Estados Unidos y Europa y ante los refugiados/damnificados comete desatención.

A partir de la observación participante que se llevó a cabo por casi cuatro años, en un contexto de confianza, los nietos y amigos de los nietos de refugiados narraron la tarde en que el abuelo $\mathrm{H}$ mostró sus heridas de guerra. Fascinados por la supervivencia de aquel que, según ellos, tenía el cuerpo cubierto de balas: "una bala le atravesó el cuerpo, una herida de cuchillo le rodeaba el pecho, está lleno de heridas", era indudable para ellos que se trataba de un héroe, guerrero y superviviente. Poco después mantuve una charla con su esposa y ella me dijo lo que los nietos y sus amigos me habían relatado con fascinación. El abuelo había sido soldado del rey Sihanouk. Este abuelo/soldado/héroe de mis alumnos fue quien lideraba las excursiones a las oficinas de la ONU, cuando la comunidad no se encontraba conforme. El liderazgo que este soldado tenía era muy bien descripto por mis alumnos, quienes fueran miembros o no de la comunidad aceptaban aquella reputación de liderazgo y la reproducían. Todo indicaba que yo debía hablar con él para obtener información interesante. La insistencia de mis alumnos y de los miembros de la comunidad me indicaba que "el abuelo H" o "el soldado del Rey" poseía la supremacía en la mirada acerca del pasado, es decir, la versión dominante. Poco después de haber concertado una entrevista con él, murió de un infarto. Nunca pude entrevistarlo, pero más tarde, entrevisté a su esposa quien parece haber heredado tal supremacía respecto al relato de aquel pasado en Camboya. Él era conocido en el barrio y en el centro de Longchamps, pues vendía muñecas de lana, tejidas por las mujeres de la comunidad.

Al llegar a la Argentina, la comunidad recorrió una larga trayectoria por diversos pueblos de la provincia de Buenos Aires: Tres Arroyos, Necochea, Pilar, Las Heras, Pehuajó, de todos ellos se retiraron a pedido de la comunidad en conjunto. Una persona de la comunidad se constituyó en vocero para solicitar y lograr el cambio de localización: el soldado del rey. Él encabezaba las negociaciones y oficiaba de interlocutor ante las autoridades. Los reiterados pedidos de cambio, así como la incomodidad por el lugar asignado, fue una constante en los grupos de refugiados laosianos y camboyanos, tal como expresa Page Poma en su tesis para el caso de los laosianos de Posadas.

\section{Violencia}

Se han rescatado algunas características históricas y territoriales en Camboya a partir de la década de 1960, especialmente aquellas que se vinculan a la expulsión y trayectorias de la comunidad de refugiados, haciendo visible la trasposición de vivencias de allá hacia acá. Algunas de ellas cargadas de violencia. El uso de la fuerza para derrocar el gobierno camboyano, dominar a los seguidores de Lon Nol y por tanto a los norteamericanos, constituyó tanto al 
Refugiados camboyanos en Longchamps: trayectorias desde Indochina hasta Argentina LAURA PUGA

golpe de estado como al gobierno de Pol Pot. La violencia relatada tanto en la bibliografía histórica como en el trabajo de campo se puede reflejar en actitudes que no pueden ser entendidas sin conocer aquel pasado. Esta violencia reflejada en el cuerpo de algunos de los sobrevivientes, componen e incluso han determinado algunas entrevistas.

Durante dos años los mediodías de los miércoles salían a buscar algo de comer y yo hacía trabajo de campo. Me instalaba en la plaza Rayo de Sol, frente a la escuela primaria $n^{\circ} 60$. Allí, uno de esos mediodías, entablé conversación con una mujer que integra este colectivo camboyano, a quien llamaré $\mathrm{S}^{19}$. Aquel mediodía, hablaba con ella de su parecer respecto a las creencias religiosas hinduistas de sus padres, yo la escuchaba entretanto tenía la intención de obtener alguna entrevista con otro camboyano de la primera generación.

Mientras S hablaba del budismo de sus padres, aumentaba mi ansiedad por encontrar el momento adecuado para pedirle que me ayude a conseguir tal entrevista. Esa ansiedad me hizo perder el registro de lo que sucedía a mi alrededor. Llevada por esa inquietud, le pregunté. No dudó ni un instante y señalando con un gesto de su cabeza (sus brazos estaban sosteniendo al bebé que no tenía aún dos meses) respondió: "mirá, ahí tenés a uno". Apenas giré la cabeza hacia la derecha, vi una escena a pocos metros de donde estábamos paradas. Se trataba de un varón de unos 60 años aproximadamente, bajo, de un metro cincuenta y cinco centímetros de altura, vestido con una remera sin mangas, musculosa de un cuadro de futbol. Él estaba de pie en la calle y hablaba con tres muchachos jóvenes que se recostaban sobre el muro de la escuela.

Ellos eran entre 20 y 30 centímetros más altos y su diferencia de estatura se acentuaba, pues los tres jóvenes estaban sobre la vereda, considerablemente más alta. Ninguno de los tres parecía tener intensión de emitir palabra respecto de lo que el más bajo decía. Los tres tenían una actitud corporal similar, manos en los bolsillos o tras de su propio cuerpo, hombros caídos y dos de ellos apoyaban sus espaldas sobre el muro. Mendoza Reyes (2012) dice que "La proxémica es el estudio de la forma en que las personas utilizan el espacio (personal y/o social) para comunicarse". En su interpretación acerca de las formas de "ocupar" lugar, se entiende que la distancia entre los tres jóvenes y el adulto camboyano era una distancia social. Esta distancia social es de uno a dos metros y medio, y marca el límite a partir del cual la otra persona no se siente

19 "S" es la mamá de una de mis alumnas, tiene entre 32 y 35 años, nació en Argentina de padre y madre camboyanos recién llegados. Sus dos hijas tienen papá criollo y hablan en perfecto "argentino". Comprende lo que sus padres le dicen, es capaz de hablar no muy fluidamente la lengua camboyana, pero les responde en español. La conocí el día que acompaño y presentó a ChS, quien es su madre. S tiene dos hijas, una es alumna en la escuela secundaria $n^{\circ} 64$ y tiene 14 años, la otra era recién nacida en el momento de conocerla. 
afectada por nuestra presencia. Estos tres jóvenes, a pesar de superar esa distancia, sí parecían estar afectados por la presencia del mayor.

Desconociendo en aquel momento lo expresado por Mendoza Reyes, no dudé en comprender que se trataba de una situación totalmente dominada por el bajo, mayor. Él hablaba con voz firme y gesticulaba con los brazos, parecía ocupar más lugar que los otros tres. Tenía los hombros erguidos, sacaba el pecho en una actitud amenazante. Nada de lo que decía podía parecer una amenaza, se trataba de una charla superficial, vinculada al futbol. Sin embargo, la escena era claramente de subordinación de los jóvenes hacia él. No me animé a interrumpir, ni a esperar a que termine el monólogo, me intimidó su actitud. El varón bajo se impuso más allá de sus oyentes.

Me paralicé. No puedo decir que su actitud fuera amenazadora, pero me sentí sorprendida y acorralada ante la propuesta de $\mathrm{S}$; aquella situación era evidentemente intimidante para mí. En ese momento, sentí que S había disfrutado mi sorpresa y la notoria negativa a abordar a aquel potencial informante. Tiempo más tarde me acordé de que cuando salieron de Camboya, llevaron consigo ciertas marcas de violencia. Aquella escena pudo ser otra forma de actuar lo que ya había sido actuado desde su llegada al barrio, ciertas posturas corporales de defensa, que pueden percibirse como agresivas. Tal como expresó $\mathrm{SMa}^{20}$, cuando los definía como amenazantes, ella dijo: "era difícil relacionarse con ellos al principio, metían miedo".

Ya se ha mencionado que el Estado argentino tuvo un doble gesto con relación a los refugiados. Este grupo fue mostrado internacionalmente como grupo vulnerado, explotado y perseguido por los ejércitos comunistas en uno de los más violentos regímenes del siglo Xx. Por otro lado, abandonados en un contexto en el cual nadie conocía su condición de refugiados por ACNUR. Esta situación vivida por los vecinos y por los mismos refugiados a su llegada, pudo determinar ciertas formas de relacionarse que no fueran "amables", ni de bienvenida.

Es posible también que esto facilitara el control de su trabajo y perpetuara la condición de sometimiento en el barrio receptor, pues difícilmente los ayudaran a conseguir trabajo, a ubicarse en el barrio o a otra colaboración que cualquier vecino podría estar dispuesto a realizar. Sin embargo, los vecinos generaron imaginarios adjudicados a la comunidad. Esos imaginarios no son más que la transferencia hacia el "otro" de prácticas que son propias y no necesariamente de aquel "otro" al que se las conferimos. Esta idea que Trinchero (2000) aplica a los americanos nativos, puede otorgar sentido a algunos de los

\footnotetext{
${ }^{20} \mathrm{SMa}$ es una mujer que tiene algo menos de 60 años, en el momento de realizar el trabajo de campo. Mantuve contacto con ella y tuve la posibilidad de entrevistar pues está vinculada a la comunidad educativa de la escuela primaria $\mathrm{n}^{\circ} 60$, vivía en el barrio desde su infancia en la década de 1960.
} 
Refugiados camboyanos en Longchamps: trayectorias desde Indochina hasta Argentina LAURA PUGA

imaginarios que el barrio adjudica a la comunidad. Pues en este caso, al igual que a los "indios", a los desconocidos "orientales", es decir, a los integrantes de la comunidad en estudio, también se los asocia con estigmas.

\section{Conclusiones}

A manera de conclusión podríamos decir que la violencia vivida por quienes fueran refugiados y la padecieran en Camboya, así como la larga historia de ocupaciones, guerras y gobiernos despóticos, puede reflejarse tanto en la bibliografía académica como en el trabajo etnográfico. Es por ello por lo que se hace posible otorgar sentido a frases, gestos, comportamientos corporales, en los que pueden expresar la crueldad padecida. Es posible advertir también que los lazos comunitarios han tenido un importante rol en este conflicto. Y que aquellas formas de violencia afectaron a esta comunidad de tal manera que sus potencialidades presentes o futuras se ven afectadas y con seguridad representadas en sus narraciones. Concluyendo que la violencia permanece en la vida de los refugiados tomando formas muy varias y representadas de muy diversas maneras.

Tanto durante la investigación, como durante la elaboración de este trabajo se encuentran muy escasos trabajos académicos relacionados con esta minoría étnica. Se han incluido antecedentes de trabajos antropológicos, geográficos e históricos realizados acerca de otras minorías étnicas residentes en el país, para entender y/o dar sentido a las trayectorias de vida del grupo en estudio. Sin embargo, todo parece indicar que está en aumento la inclusión de estas minorías en la investigación académica.

En 1980, cuando Argentina recibió a refugiados de Camboya y Laos, se encontraba bajo el gobierno de la dictadura cívico-militar vigente entre 1976 y 1983. Sus características represivas y su uso del terrorismo de Estado suponen que recibir refugiados no fue una prioridad. Aquella dictadura tuvo razones para acordar la llegada de estos refugiados. En este hecho fue fundamental la búsqueda de legitimidad internacional. Entonces, Argentina se convertía en un país expulsor de población por causas políticas y económicas, al tiempo que recibía refugiados de Indochina.

Por otro lado, las comunidades laosianas y camboyanas alojadas en Misiones se han consolidado como mano de obra barata y marginada en explotaciones agrarias. Esto es funcional como herramienta disciplinaria del Estado, pero también como mecanismo de enriquecimiento de élites locales y conniventes con la dictadura cívico-militar. La responsabilidad que el Estado nacional tuvo con los refugiados lo convierte en partícipe de la explotación económica $\mathrm{y} / \mathrm{o}$ segregación social padecida por ellos. Las maneras de contratación o en que estas personas fueron forzadas a incluirse como mano de 
obra en propiedades preestablecidas por los gobiernos locales podría ser una responsabilidad más del Estado dictatorial que nunca fue juzgada.

\section{Referencias bibliográficas}

AA.VV. (s/f). Diccionario enciclopédico hispanoamericano de literatura, ciencias, artes, tomo IV. Barcelona: Montaner y Simón.

Alto Comisionado de las NACIONES UnidAs PARA los REFUGIAdOS (2000). La situación de los Refugiados en el mundo 2000. Cincuenta años de acción Humanitaria. www.acnur.org/publicaciones-SRM/cap43.php

ANDERSON, B. (1993). Comunidades Imaginadas. Reflexiones sobre el origen y la difusión del nacionalismo. Buenos Aires: FCE.

Brow, J. (1990). Notes on community, hegemony, and the uses of the past. Antropological Quarterly, 63(1), 1-6.

CicognA, M.P. (2006). Exiliados, solicitantes de refugio y refugiados en Argentina Una cronología del siglo XX. VII Jornadas de Sociología. Facultad de Ciencias Sociales, Universidad de Buenos Aires.

CONVENIO Almirante BROWN - FADU/UBA - FUndACión Metropolitana (2010). Programa para el fortalecimiento institucional del Municipio de Almirante Brown. Diagnóstico urbano de Almirante Brown, etapa I.

DeBAnDi, N. (2013). La expulsión de inmigrantes en Francia. ¿Interrupción o parte de las carreras migratorias? Argumentos, 15.

Díaz Polanco, H. (1988). La cuestión étnico-nacional. Fontamara. México.

Golluscio, L.; Briones, C.; Lenton, D.; Ramos, A. y SPOliansky, V. (1996). El discurso en los procesos de formación de comunidad. Lengua y Literatura Mapuche, 7, 87-102. Universidad de la Frontera. Temuco, Chile.

JELIN, E. (2002). Los trabajos de la memoria. Madrid: Siglo XXI.

KIERNAN, B. (2010). El régimen de Pol Pot: raza, poder y genocidio en Camboya bajo el régimen de los Jémeres Rojos, 1975-1979. Buenos Aires: Prometeo Libros.

MARTinO, M.C. (2015). Hacia una contextualización de las migraciones de caboverdeanos en el Gran Buenos Aires a partir de sus diferencias generacionales. Universitas Humanistica, 80, 107-131.

MENDOZA REYES, L. (2012). Lenguaje corporal como medio de comunicación. Lingüistica aplicada. Universidad Autónoma Metropolitana. México.

PACECCA, M.I. Y COURTIS, C. (2008). Inmigración contemporánea en Argentina: dinámicas y politicas. Santiago de Chile: Centro Latinoamericano y Caribeño de Demografía (CELADE). División de Población. CEPAL

PACECCA, M.I. (2013). El trabajo adolescente y la migración desde Bolivia a Argentina: entre la adultez y la explotación. Antropología y Proceso Migratorios, 7. 
Refugiados camboyanos en Longchamps: trayectorias desde Indochina hasta Argentina LAURA PUGA

Page Poma, E. (2015). La integración de los refugiados laosianos de Posadas. Tesis de Licenciatura en Ciencias Antropológicas. Departamento de Antropología. Facultad de Filosofía y Letras, UBA.

Quijano, A. (2000). Colonialidad del poder y clasificación social. Journal of World Systems Research, 6(2), 342-386.

Ministerio Del InTERIOR (2012). Refugiados del Sudeste Asiático en la Argentina. 30 años de Historia. Serie de documentos de la Dirección Nacional de

Población. http://www.mininterior.gov.ar/poblacion/pdf/Documento07.pdf

Strahler, A. (1982) Geografía física. Editorial Omega.

Trinchero, H. (2007) Aromas de lo exótico (retornos del objeto) para una crítica del objeto antropológico y sus modos de reproducción. Colección complejidad humana. Buenos Aires.

Weber, M. (1944) Economía y sociedad. Esbozo de sociología comprensiva. Fondo de Cultura Económico. México.

Wejebe Cobo, J. 7 de marzo de 2012). El año cero de Pol Pot. Diario 90. Defendiendo la verdad desde La Habana. Cuba. https://eladversariocubano.net 

